GLOBAL JOURNAL OF EDUCATIONAL RESEARCH VOL 12, 2013: 47-54

\title{
CHILD ABUSE AND ACADEMIC PERFORMANCE OF SECONDARY SCHOOL STUDENTS IN CENTRAL SENATORIAL DISTRICT OF CROSS RIVER STATE.
}

P. A. OKPECHI

(Received 5, March 2012; Revision Accepted 27, March 2013)

\begin{abstract}
The need to provide research information about the prevalence of street hawking, its effects and educational factors was the focus of this research. The focus of this study is on street hawking as an aspect of child labour, abuse and neglect. The goal of the research on child abuse and academic performance of children who participate in it as a routine scholars and people have defined child labour in several ways. In a nutshell it is the exploitation of children, premature assumption of adult roles on the part of children; working long hours for low wages.in the central senatorial district in Cross River State of Nigeria, has three main purposes: to identify the extent of students involvement in street hawking. Secondly, determine the factors, which influence students involvement in street hawking and lastly to compare the relationship between street hawking and academic performance of those who are engaged in the activities with those who do not. The data used in testing the hypothesis were gotten from the post-test scores of all the subjects. Hypothesis were tested at. 0.5 level of significance. Based on the results of the hypotheses, recommendations were made.
\end{abstract}

KEY WORDS: Child Labour, Abuse, Street Hawking, Academic Performance and Effect.

\section{INTRODUCTION}

Differences in academic performance of students under the same conditions of teaching, have, overtime given the researcher a cause for concern. To establish the cause of low or high academic performance have been the target whereas the researcher interaction with students of high academic performance shows that they came from well-to-do homes, live comfortable life and are exposed to condusive environment. Interaction with students of poor academic performance shows that most of them came from poor or broken homes, with little or no means of livelihood, hence they need to fend for themselves. This exposes them to emotional and psychological instability. According to United Nations (1959), the issue of child abuse is something that has been in existence for many years. In Nigeria, Anukam (1986), Waboso (2000), Esu (2002) and the international society for the prevention of child abuse and neglect
(ISPCAN) which led to the formation of the African Network for the prevention and protection against child abuse and neglect (ANPPCAN) frown at child abuse. All these groups condemn child abuse. A child is said to be abused if he or she is denied basic rights like any other citizen. In essence, he is subjected to a lot of maltreatment and forced to live under the most un-conducive atmosphere. Child abuse takes many forms, for example, child labour, sexual abuse, child deprivation, neglect, physical and psychological child abuse, children used in rituals, battering, early marriage, child soldering, child prostitution, children used in street hawking, human trafficking, child abandonment to mention but a few (Waboso, 2000, Okpechi, (2005).

It is common in the society to see school children hawking one type of goods or another. The researcher kept on imagining why these children are not in school. Again, if at all they attend school, do they perform well? As a

P. A. Okpechi, Educational Foundations and Administration, Cross River University of Technology, (Crutech) Calabar 
teacher, the researcher had on several occasions observed some students in class sleeping while teaching is going on, when asked why they sleep at that time, their answers most of the times is always that they do hawking before coming to school and so they are very weak. The researcher also observed that most students do not perform well academically, and therefore started to ponder whether their poor performance could be attributed to their involvement in street hawking.

For a child to perform well academically, he needs a stable mind and a motivating environment. These conditions often elude some children particularly those from low-income parents. Child abuse can have a drastic consequence on the future life of the child. It is dehumanizing. It engenders low self-concept, promotes inferiority complex, belittles the individual, as well as degradation of ones personality (The Guardian, Sept. 11, 2000).

\section{Statement of The Problem}

There is clear evidence that children who are involved in street hawking are generally at risk for a variety of psychological and developmental outcome due to excessive exposure to hazard. They also function poorly intellectually and are almost mentally retarded (Ebigbo, 1986). Therefore the problem of this study is posed as a question.

How does child labour as an aspect of child abuse reflict on the academic performance of students who engage in it, in the central senatorial district of Cross River State of Nigeria?

\section{Purpose of The Study}

The purpose of this study is to:

1. Determine the factor, which influence children involvement in street hawking.

2. Investigate the influence of street hawking, on academic performance of secondary school students in central senatorial district of Cross River State.

3. Compare the relationship in performance between street hawking children engaged in the activities with those who do not.

\section{Research Hypotheses}

The following hypotheses were formulated and statistically tested at probability level of .05.
1. Street hawking is not significantly dependent on the socio-economic status of parents/guardians.

2. There is no significant relationship in the mean academic performance scores of students who engaged in street hawking compared with their counter parts who do not engaged in such activity.

\section{Significance of The Study}

The present study is considered significant, as it will provide information on the incidence and level of involvement among secondary school students in street hawking in the central senatorial district of Cross River State, as well as some factors, which help to influence this practice. It would further reveal how street hawking affect or influence the academic performance of secondary school students.

Information on the incidence will sensitize the family/guardians and relevant policy-makers to the magnitude of street hawking as an aspect of child abuse and neglect in the area of study.

Furthermore, the study would review the pattern of relationship between street hawking , and the academic performance of secondary school students. If it is found out that child labour has adverse effects on the academic performance of secondary school students, parents may be told sufficiently to withdraw children from such activities. This same information will sensitize the government to formulate laws to curb the excesses of street hawking and make it compulsory for parents/guardians to send their children/wards to school.

\section{Research Design}

This survey research was aimed at investigating incidence of a particular aspect of child abuse, called street hawking, among secondary school students in central senatorial district of Cross River State of Nigeria. The survey design was deemed appropriate because, according to Denga and Ali, (1998), in survey studies, ñSubjects are observed in their natural settingò The present study involved fact-finding regarding the incidence of child labour in relation to academic performance of secondary school students who engaged in the activities and those who do not.

Again the researcher decided to choose survey method, as it is economical in the sense that a study of representative sample will permit 
the generalizations to populations that would be too expensive as a whole.

\section{Research Area}

This study was confined to central senatorial district of Cross River State. Cross River State is one of the thirty six (36) states that made up the Federal Republic of Nigeria. It is located in the Southern part of the country. The state is made up eighteen (18) local government areas and is divided into three (3) senatorial districts namely, North, central and south senatorial districts.

Central Cross River as the name implies, occupies the central position of the state with six (6) local government areas, i.e. Abi, Boki, Etung, Ikom, Obubra and Yakurr local government areas. The district is bounded to the north by Ogoja, Obudu and Obanliku Local Government areas; the Republic of Cameroon to the East, Ebonyi state to the West and to the South, by Biase and Akamkpa Local Government Areas. Central Cross River has a total population of 677.993. Males are 338575 while339418 are females (1991 National Population Census figure).

The major occupation of the people is peasant farming, trading, and fishing with a few in the civil service.

\section{Population of The Study}

The population of the study was made up of all senior secondary school class I (SS1), students, in the central senatorial district for $2011 / 2012$ academic sessions. There was a total of eighty eight (88) public owned secondary schools spread all over the six local government areas under the management of Secondary Education Board (SEB). The populations in these schools stand at 48,612 with 26,299 males, which represent $54.1 \%$ and 22,313 females which represent $45.9 \%$ respectively. The total population of senior secondary class I (SS1) students that the study is concerned with is 48,612 (SEB Oct, 2012 monthly returns).

The researcher consciously make the choice of SS 1 students because of their junior secondary school ( JSS III) 2011/2012 result which is a state examination that can be used in measuring their academic performance. As shown in table 5 and 6

\section{Sampling Procedure}

In composing the sample, the stratified random technique was used. The area of study was stratified into six (6) local government areas namely: Abi, Boki Etung, Ikom, Obubra and Yakurr for even representative twelve (12) secondary schools are used for the study, whichis two (2) secondary schools from each local government area.

From each of the two schools selected from the six local government areas, one school was located from the urban and the other school in the rural area. So that the outcome of the result could be generalized.

In order to select the subjects (students) all the (SS 1) students in the selected schools were pooled together in each school and made to pick from a basket with pieces of folded paper bearing Yes or No. those that picked no were discarded and those who picked yes were automatically identified as subjects of this study.

\section{The Sample}

As explained above. The sample was selected from the twelve (12) secondary schools designated as urban and rural schools. These schools were co-educational. Thirty (30) students were selected from each of these schools. This brought the sample size to 360 . 
The schools were selected from each of the six (6) Local Government Areas. See table one (1)

Table 1

School, sample/sex and age of subjects

\begin{tabular}{|l|l|l|l|l|l|}
\hline LGA & SCHOOLS & MALE & FEMALE & TOTAL & AGE \\
\hline \multirow{3}{*}{ ABI } & School A & 17 & 13 & 30 & $15-17$ \\
\cline { 2 - 6 } & School B & 14 & 16 & 30 & $15-18$ \\
\hline \multirow{3}{*}{ BOKI } & School A & 12 & 18 & 30 & $15-18$ \\
\cline { 2 - 6 } & School B & 13 & 17 & 30 & $15-17$ \\
\hline \multirow{3}{*}{ ETUNG } & School A & 16 & 14 & 30 & $15-18$ \\
\cline { 2 - 6 } & School B & 12 & 18 & 30 & $15-17$ \\
\hline \multirow{3}{*}{ OBUBRA } & School A & 17 & 13 & 30 & $15-17$ \\
\cline { 2 - 6 } & School B & 14 & 16 & 30 & $15-17$ \\
\cline { 2 - 6 } & School A & 13 & 17 & 30 & $15-17$ \\
\hline \multirow{2}{*}{ YAKURR } & School B & 14 & 16 & 30 & $15-18$ \\
\cline { 2 - 6 } & School A & 12 & 18 & 30 & $15-18$ \\
\hline \multicolumn{2}{|l|}{ TOTALol B } & 16 & 4 & 30 & \\
\hline
\end{tabular}

\section{Instrumentation}

The major instrument used for this research was the questionnaire. It contained forty-four items (44) and is divided into two parts
(2) in all. The purpose of the questionnaire was to determine the degree of involvement in street hawking of secondary school students in the central senatorial district of Cross River State

Part 1

Section A: Measured personal data of the students e.g. (Age, Sex, school, class etc)

Part II

Section A: $\quad$ Measured socio-economic status of parents

Section B: $\quad$ Measured level of involvement in street hawking.

The questionnaire was designed with the help of other experts in the area of statistics, some of whom were academic staff of the University of Calabar. Most of the items were based on the researcher⿳⺈ personal observation and from data gathered in the course of reviewing related literature.

Validity

After the construction of the questionnaire, it was given to colleagues (lecturers) in the department to assess its appropriateness. They offered useful suggestions and criticisms after which the items were revised and presented in the final draft.

\section{Reliability}

To ascertain the reliability of the research instrument, a pilot testing was carried out using fifty (50) senior secondary one students (SSI), in one of the secondary schools in Ugep town. 
The questionnaire was administered twice to obtain the reliability co-efficient

Table 2

Test-retest reliability co-efficient of the research instrument.

\begin{tabular}{|l|l|l|l|l|l|}
\hline VARIABLES & $\begin{array}{l}\text { No. of } \\
\text { items }\end{array}$ & No. of testing & $\mathbf{X}$ & SD & $\mathbf{R}$ \\
\hline $\begin{array}{l}\text { Socio-economics Status of } \\
\text { parents }\end{array}$ & 14 & $1^{\text {st }}$ & 23.57 & 4.40 & \\
\cline { 2 - 6 } $\begin{array}{l}\text { Level of involvement in street } \\
\text { hawking }\end{array}$ & & $2^{\text {nd }}$ & 23.79 & 4.55 & 92 \\
\cline { 2 - 6 } & 30 & $1^{\text {st }}$ & 55.55 & 22.70 & 98 \\
\hline
\end{tabular}

\section{Data Collection Procedure}

The researcher used one instrument to gather information for the study; this instrument was the questionnaire.

The questionnaire was administered in the twelve (12) secondary schools selected for the study. It was administered in the various schools with the help of the teachers therein.

After the students had finished responding to the instrument, the researcher went round and collected the questionnaire. They were scored and recorded. The mean and standard deviation of the score were computed for the purpose of analysis.

\section{Procedure For Testing Hypotheses}

The hypotheses formulated for the study guided the process of data analysis. Twonull hypotheses were postulated. The variables in such hypotheses identified and the test statistics used to test the hypotheses stated.

\section{Hypothesis I}

The level of student $\hat{\Phi}$ involvement in street hawking is not significantly dependent on the socio-economic status of their parents

The independent variable in this hypothesis is socioeconomic status of studentsô which had three classifications of low, medium and high in the study. The dependent variable in this hypothesis is studentsô involvement in the street hawking. The appropriate statistical analysis technique used in testing this hypothesis was the one-way analysis of variable (ANOVA) with the associated $\mathrm{F}$ test.

The results of the analysis are presented in table $3 a$

Results of analysis of variable of the influence of parental socio-Economic status of student's involvement in street hawking

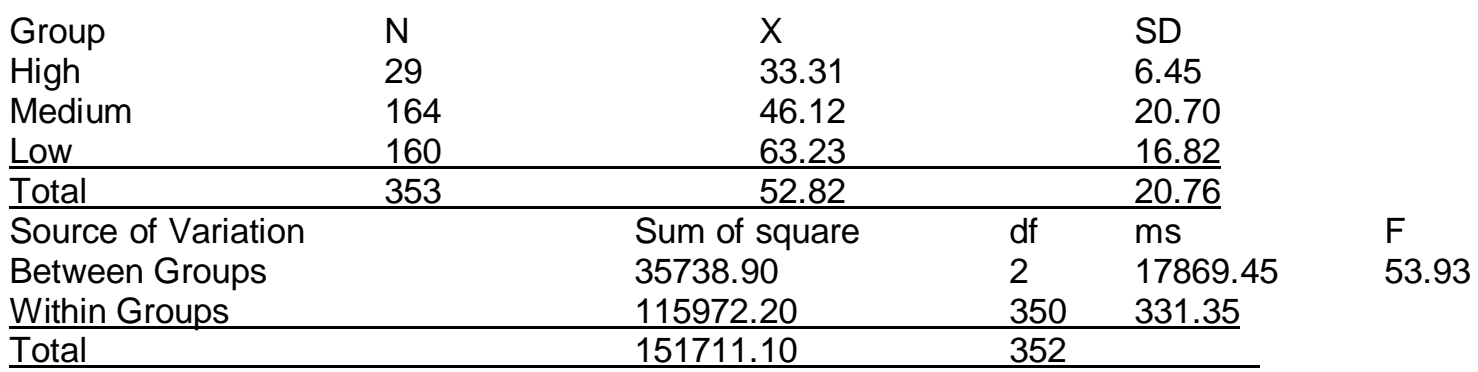

Significant at .05

The significance influence of parental socio-economic status on students involvement in street hawking was further explored with the Fisherế Least significance Difference (LSD) multiple pairwise comparisons presented zin table 3a. The result in that table showed that the level of involvement in street hawking of students from low parental socio-economic status

$\overline{(X}=63.23)$ is significantly higher than the level of involvement in street hawking from medium $\overline{(X=}$ 46.12) and high 
$\overline{\bar{X}}=33.31)$ parental socio-economic status (significant $\mathrm{T}$ ï values of 8.46 and 8.14 respectively). Also, the level of involvement in street hawking of students from medium parental socio-economic status $(\bar{X}$ $=46.12)$ is significantly higher than that of students from high parental socio-economic status $\overline{(X}=$ 33.31). The significant $t-v a l u e$ of 3.49 confirms this. With this result, the null hypothesis was rejected while the alternate was accepted.

$\begin{array}{llll}\text { Table } 4 & & \\ \text { Socio - Economic status of parents } \\ \text { Socio-economic } & \text { High }(\mathrm{n}=29) \text { Medium }(\mathrm{n}=164) \text { Low }(\mathrm{n}=160) \\ \text { Status } & & -12.81^{\mathrm{b}} & -29.92 \\ \text { High } & 33.31^{\mathrm{a}} & 46.12 & 17.11 \\ \text { Medium } & -3.49^{\mathrm{c}} & -8.46^{*} & 63.23 \\ \text { Low } & -8.14^{*} & \end{array}$

a. $\quad$ - $\quad$ Group means are placed along the diagonal.

b. $\quad$ - $\quad$ Difference between group means are above diagonal.

c. - $\quad$ - Fisher $\hat{\mathbf{s}} \mathrm{t}$-value are below the diagonal.

* $\quad$ - $\quad$ Significant at .05 level (Critical $t=1.96)$

Table 4a

Fisher's least significant difference multiple comparison analysis of the means of the influence socio-economic status of parents on students street hawking.

Hypothesis II

There is no significant relationship between the studentsôlevel of involvement in street hawking, and their academic performance.

The independent variable in this hypothesis is level of involvement in street hawking, while the dependent variable is the mean academic performances. Students in the sample were grouped into three, based on their scores involvement in street hawking. The scores were: 1 ï 45, low level; 46 i 75 , moderate level; and 76 and above, high level.

The academic performanceused in this study was the results of ( JSS III) 2011/2012 released by the Cross River State Ministry of Education which came in the form of letter grades (A, C, P, F).

\section{Table 5}

The appropriate statistical analysis technique used to test the hypothesis was $3 \times 4$ contingency chisquare $\left(x^{2}\right)$ analysis of the relationship between level of involvement in street hawking and academic performance of students in English Language.

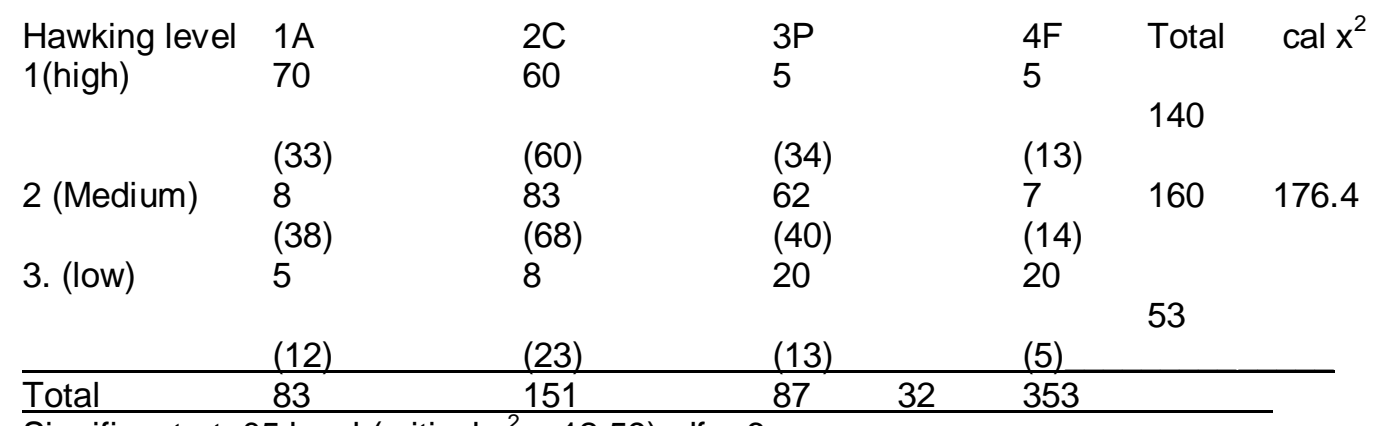

Significant at .05 level (critical $\mathrm{x}^{2}=12.59$ ); $\mathrm{df}=6$ 
Table 6

Result of contingency chi-square $\left(x^{2}\right)$ analysis of the relationship between level of involvement in street hawking and academic performance of students in Mathematics.

\begin{tabular}{|c|c|c|c|c|c|c|}
\hline \multirow{3}{*}{$\begin{array}{l}\text { Hawking level } \\
1 \text { (high) }\end{array}$} & $1(A)$ & $2(C)$ & $3(P)$ & $4(F)$ & Total & cal $x^{2}$ \\
\hline & 50 & 70 & 10 & 10 & & \\
\hline & (25) & (56) & (40) & (19) & & \\
\hline \multirow[t]{2}{*}{2 (medium) } & 7 & 64 & 80 & 9 & & \\
\hline & (29) & (64) & (45) & (22) & 160 & 179.4 \\
\hline \multirow[t]{2}{*}{3 (Low) } & 6 & 7 & 10 & 30 & & \\
\hline & (9) & (21) & (15) & (8) & 50 & \\
\hline Total & 63 & 141 & 100 & 49 & 353 & \\
\hline
\end{tabular}

The results in table 5 and 6 have shown that the calculated $x^{2}$ value of 176.4 and 179.4 are each greater than the critical $X^{2}$ value of 12.59

The null hypothesis was therefore rejected. Level of involvement in street hawking has a significant relationship with academic performance. As the two tables showed, the number of students increased with the level of involvement in street hawking.

Few of the students who passed r̃Aòwere involved in street hawking.

\section{SUMMARY OF THE FINDINGS}

1. The level of student $\hat{\Phi}$ involvement in street hawking is significantly dependent on the socio- economic status of their parents

2. There is a significant relationship between street hawking and academic performance of secondary school students in the area of study. Compared with their counter parts who do not engaged in such activities.

\section{CONCLUSION}

Result of this study affirmed that children who engage in street hawking performed academically poorer than their counter parts who do not take part in the activities. The poor performance was attributed to theinability of the hawkers to concentrate on their school work as opposed to the non-hawkers. The street hawkers combine hawking with schoolwork and often then not, hawked before going to school in the morning and immediately after school dismissed. They have little or no time to do their class assignments.

\section{RECOMMENDATIONS}

On the basis of the findings of this study and their implications, the following recommendations were made:

It was time that the Federal, State, Local Government, Non-governmental organizations such as the National Council for women societies (NCWS), African Network for the prevention and protection Against Child Abuse and Neglect (ANPPCAN), Planned parenthood Federation of Nigeria (PPFN), World Organization for Early childhood Education (WOECE), Rotary/Inner wheel clubs, Lion/Lioness clubs, should also be concerned over the plight of the children hawkers. They should use their good offices to organize seminars, conferences, workshops to educate parent/guardians on the need to have a sizable family, the need for family planning, the ills of Children Street hawking particularly on the health and academic performance of the children involved in it. 


\section{REFERENCES}

Anukam, H. O., 1986. Child Abuse andlabour; The Nigerian case, Enugu: Onii publishing house.

Denga, I. D. and Ali, A., 1998. An Introduction to Research methods and statistics in Education and social science.Calabar: Rapid Educational publishers.

Ebigbo, P. O., 1986 May $4^{\text {th }}$, r̃Child Abuse: the Nigeria Situationò Weekly star newspaper, p.7.

Esu, A., 2002 October $5^{\text {th }}$, r̃Child labour and Abuse: A barrier to Children $\hat{\Phi}$ growth and developmentò $A$ paper presented at the FAIWA pre-Home coming Annual Delegates conference held at Women Development Centre, Calabar.
Okpechi, P. A., 2005. Child Abuse and Academic performance of Secondary School Students of Central Senatorial District in Cross River State ï Nigeria, Unpublished M.ED THESIS, Faculty of Education, University of Calabar,Calabar.

Secondary Education Board (Oct. 2012). Cross River State monthly Returns.

United Nation., 1959. The right of the child fact Sheet No. 10. New York: Information Division Publication.

Waboso, N., 2000. Child Abuse and Neglect, its effects on Nigerian Children. Unpublished research project, faculty of social science. University of Calabar, Calabar. Nigeria. 
